\title{
Penerapan Metode Haversine Formula Untuk Penentuan Titik Kumpul pada Aplikasi Tanggap Bencana
}

\author{
Abadi Nugroho ${ }^{*}$, Rio Jumardi ${ }^{2}$, Nur Fajariah Ramadhania ${ }^{3}$ \\ ${ }^{1,2}$ Sekolah Tinggi Teknologi Bontang \\ *abadi@stitek.ac.id
}

\begin{abstract}
Bontang City is located in East Kalimantan Province Indonesia is one of the most vulnerable cities of the disasters. Due to the absence of special media in the process of providing information about disaster events and gathering point information, there are many sources of unreliable news or information and the slow handling of disasters because they have to check the accuracy of disaster event information first. The purpose of this research is to create an application that can provide disaster information and find the closest gathering point using the Haversine Formula method and Google Maps technology. Haversine Formula is an equation in navigation by giving the distance of a large circle (radius) between two points on the surface of the sphere (earth) based on longitude and latitude. This application was built with Android Developer Tools with the Java programming language. The system development methodology used is GRAPPLE (Guidelines for Rapid Applying Engineering). The Grapple Method consists of 5 stages, namely Requirement Gathering, Analysis, Design, Development, and Deployment. This research only reached the Development stage. Web pages are prepared using PHP Native and MySQL programming languages as a database of this application. From the results of this research, an application was created for disaster information and a collection point to determine the closest distance to the user's location. Based on the appropriateness testing of the application of 10 respondents stated this application is suitable for use and published to the public.
\end{abstract}

Keywords: android, disaster, GRAPPLE, Haversine formula

\begin{abstract}
Abstrak
Kota Bontang terletak di Provinsi Kalimantan Timur Indonesia merupakan salah satu kota yang paling rawan terjadinya bencana. Saat ini belum ada media khusus dalam proses penyampaian informasi mengenai kejadian bencana dan informasi titik kumpul, banyaknya berita atau informasi yang tidak dapat dipercaya sumbernya dan lambatnya penanganan kebencanaan karena harus mengecek keakuratan informasi kejadian bencana terlebih dahulu. Tujuan dari penelitian ini adalah membuat aplikasi yang dapat memberikan informasi bencana dan mencari titik kumpul dengan jarak terdekat menggunakan metode Haversine Formula serta teknologi Google Maps. Haversine Formula merupakan sebuah persamaan dalam navigasi dengan cara memberikan jarak radius (lingkaran besar) antara dua titik pada permukaan bola (bumi) berdasarkan lintang dan bujur. Pembuatan aplikasi ini dibangun dengan Android Developer Tools dengan bahasa pemrograman Java. Metodologi pengembangan sistem yang digunakan adalah GRAPPLE (Guidelines for Rapid APPlication Enggineering). Metode Grapple terdiri dari 5 tahap yaitu Requirement Gathering, Analysis, Design, Development, dan Deployment. Penelitian ini hanya sampai tahap Development. Halaman web disusun dengan menggunakan bahasa pemrograman PHP Native dan MySQL sebagai database dari aplikasi ini. Dari hasil penelitian ini, tercipta aplikasi informasi bencana dan titik kumpul untuk menetukan jarak terdekat dengan lokasi pengguna. Berdasarkan dari pengujian kelayakan aplikasi dari 10 responden menyatakan aplikasi ini layak digunakan dan dipublikasikan ke masyarakat.
\end{abstract}

Kata kunci: android, bencana, GRAPPLE, Haversine formula

\section{Pendahuluan}

Indonesia merupakan salah satu negara yang rawan terjadinya bencana alam [1]. Bencana alam adalah bencana yang diakibatkan oleh alam diantaranya gempa bumi, tsunami, gunung meletus, banjir, kekeringan dan sebagainya [2]. Bencana alam dapat menyebabkan korban jiwa manusia, 
kerusakan lingkungan, kerugian harta benda dan dampak psikologis bagi penduduk sehingga dapat berdampak pada kegiatan pembangunan [3]. Dengan dampak yang bisa diakibatkan dari bencana alam tersebut maka perlu ada langkah-langkah untuk mengurangi jumlah korban jiwa yang diakibatkan oleh bencana alam.

Sejak tahun 1945 pemerintah Indonesia telah membentuk badan khusus yang menangani bencana alam yang bernama Badan Penolong Keluarga Korban Perang (BPKKP) kemudian berubah nama menjadi Badan Nasional Penanggulangan Bencana (BNPB) pada tahun 2008 [4]. Terbentunya Badan Nasional Penanggulangan Bencana (BNPB) masih menimbulkan beberapa permasalahan diantaranya belum terwujudnya regulasi turunan undang-undang penanggulangan bencana, belum optimalnya dukungan anggaran, lambatnya mekanisme proses dana penanggulangan bencana, lambatnya upaya mitigasi dan tanggap darurat bencana, lemahnya koordinasi antar instansi terkait. [5]

Pada penelitian ini peneliti tertarik untuk mencoba membantu dalam penyelesaian permasalahan yang diakibatkan oleh lambatnya upaya mitigasi dan tanggap darurat bencana. Lambatnya upaya mitigasi dan tanggap darurat bencana bisa diakibatkan karena kurangnya informasi yang bisa didapatkan oleh masyarakat, sistem peringatan dini hingga budaya mitigasi belum menjangkau seluruh masyarakat, bahkan di lingkungan aparatur pemerintahan [5]. Salah satu cara yang bisa dilakukan untuk membantu mempermudah mendapatkan informasi yaitu membuat suatu aplikasi. Pada aplikasi terdapat informasi kejadian bencana alam serta upaya evakuasi dengan memberikan informasi titik kumpul. Aplikasi yang dibuat diharapkan akan bisa membantu masyarakat dan BPBD (Badan Penanggulangan Bencana Daerah) dalam penanganan bencana alam pada suatu daerah. Berdasarkan latar belakang tersebut maka rumusan masalah dalam penelitian ini yaitu Penerapan metode Haversine formula untuk penentuan titik kumpul pada aplikasi tanggap bencana.
Landasan teori yang digunakan oleh peneliti pada penelitian ini adalah sebagai berikut:

\subsection{Aplikasi}

Aplikasi merupakan sebuah piranti lunak yang dibuat oleh sebuah perusahaan komputer yang digunakan untuk membantu mengerjakan tugas tertentu misalnya Microsoft Word dan Microsoft Excel. [6]

\subsection{Informasi}

Informasi merupakan sebuah kumpulan data yang digunakan untuk keperluan pendukung aktifvitas pengambilan keputusan. [7]

\subsection{Bencana}

Bencana merupakan sebuah kejadian yang bisa mengancam kehidupan masyarakat yang diakibatkan oleh faktor alam, faktor manusia dan sebagainya yang bisa menyebabkan korban jiwa manusia, kerusakan lingkungan, kerugian harta benda dan dampak psikologis.[2]

\subsection{Titik Kumpul}

Titik kumpul merupakan sebuah lokasi terbuka yang berdekatan dengan pusat-pusat lingkungan pemukiman yang berfungsi untuk titik pertemuan warga yang akan dipindahkan ke lokasi tertentu karena ada sebuah kegiatan ataupun bencana. [8]

\subsection{Haversine Formula}

Penelitian yang dilakukan menggunakan metode Haversine untuk menentukan jarak antara titik. Variabel masukannya pada motode haversine ini menggunakan garis lintang (longitude) dan garis bujur (lattitude) dengan mengasumsikan berntuk bumi bulatsempurna dengan. Haversine formula memberikan jarak lingkaran besar antara dua titik pada permukaan bola (bumi) berdasarkan bujur dan lintang dengan mengasumsikan jari-jari R 6.367, $45 \mathrm{~km}$, dan lokasi dari 2 titik di koordinat bola (lintang dan bujur) masingmasing adalah lon1,lat1, dan lon2, lat2. Rumus Haversine dapat ditulis dengan persamaan sebagai berikut [9]:

Rumus Haversine:

$$
\begin{aligned}
& \mathrm{X}=(\operatorname{lon} 2-\operatorname{lon} 1) * \cos ((\text { lat } 1+\text { lat } 2) / 2) \\
& \mathrm{y}=(\text { lat2-lat } 1)
\end{aligned}
$$

Keterangan:

$$
\mathrm{x}=\text { Longitude (Lintang) }
$$


$\mathrm{y}=$ Lattitude (Bujur)

$\mathrm{d}=$ Jarak

$\mathrm{R}=$ Radius Bumi $=6371 \mathrm{~km}$

1 derajat $=0.0174532925$ radian

\subsection{Android}

Android merupakan istilah dalam bahasa inggris yang berarti robot yang menyerupai manusia. Pada tahun 2005 Google secara resmi telah membeli android sehingga pengembangan android sepenuhnya berada ditangan Google. Dalam proses pengembangan sistem operasi android, dibentuklah organisasi Open Handset Alliance (OHA). Google merilis software open source untuk android, sehingga dapat berkontribusi untuk mengembangkan android. [10]

\subsection{Google Maps API}

API adalah kependekan dari Application Programming Interface. API merupakan kumpulan fungsi-fungsi bahasa pemrograman yang disediakan oleh aplikasi atau layanan agar bisa diintegrasikan dengan aplikasi atau website yang dibuat. Google API merupakan fungsi-fungsi pemrograman yang disediakan oleh Google Maps agar Google Maps bisa diintegrasikan kedalam web atau aplikasi yang dibuat. Google API dapat membantu mengetahui sebuah lokasi dengan akurat berdasarkan garis lintang. [11]

\section{Metoda Penelitian}

Dalam penelitian ini peneliti melakukan beberapa tahapan yaitu dimulai dari pengumpulan data, pengembangan sistem, analisis sistem dan pengujian sistem.

\subsection{Pengumpulan data}

Pengumpulan data yang dilakukan oleh peneliti diantaranya adalah sebagai berikut :

a. Peneliti melakukan penelitian secara langsung di kantor BPBD (Badan Penanggulangan Bencana Daerah) kota Bontang.

b. Peneliti melakukan studi literatur dari beberapa sumber di website, buku dan jurnal.

c. Peneliti melakukan wawancara dengan pegawai BPBD (Badan Penanggulangan Bencana Daerah) kota Bontang terkait dengan pelaporan kejadian bencana yang terjadi di kota Bontang.

\subsection{Pengembangan Sistem}

Pengembangan sistem yang digunakan pada penelitian ini menggunakan metode Guidelines for Rappid APPLication Engineering (GRAPPLE) dan pemodelan menggunakan UML. Metode GRAPPLE terdiri dari 5 tahap yaitu Requirement Gathering, Analysis, Design, Development, dan Deployment [12]. Penelitian ini hanya sampai tahap Development.

\subsection{Analisis Sistem}

Analisis sistem yang digunakan pada penelitian ini yaitu dengan metode PIECES (performance, information, economics, control, efficiency, dan services).

\subsection{Pengujian Sistem}

Pada saat pengujian sistem, peneliti menggunakan metode pengujian black box. Pengujian black box ini diperlukan untuk megukur kinerja aplikasi yang sudah dibangun dan memastikan semua fitur telah berfungsi dengan baik.

\section{Hasil Penelitian}

\subsection{Perancangan Data}

Pada saat menentukan titik kumpul diperlukan sebuah lokasi titik awal yang berfungsi sebagai acuan dan titik tujuan. Pada penelitian ini diujikan titik awal berada pada Jl. Ir. H. Juanda (Kantor BPBD) sedangkan titik tujuannya berada pada kelurahan Tanjung Laut. Langkah-langkah perhitungannya adalah sebagai berikut :

a. Menentukan lokasi awal pencarian

Lokasi : Jl. Ir. H. Juanda (Kantor BPBD)

Lon1 : 117.49063

Lat $1: 0.124982$

b. Menentukan Lokasi Tujuan

Lokasi : Taman Tanjung Laut

Lon2 : 117.48472775

Lat $2: 0.12137582$

c. Merubah derajat keradian

Lon $1=117.49063 \times 0.0174532925$ radian

$=2.0505983314$ radian

Lat1 $=0.124982 \times 0.0174532925$ radian

$=0.0021813474$ radian

Lon $2=117.48472775 \times 0.0174532925$

radian $=2.0504953177$ radian

Lat $2=0.12137582 \times 0.0174532925$

radian $=0.0021184077$ radian 
d. Mencari Nilai X dan Y

$$
\begin{aligned}
& \mathrm{X}=(\operatorname{lon} 2-\operatorname{lon} 1) * \cos ((\text { lat } 1+\text { lat } 2) / 2) \\
& =(2.0504953177-2.0505983314) * \cos \\
& ((0.0021813474+0.0021184077) / 2) \\
& =0.0001030136
\end{aligned}
$$

$$
\begin{aligned}
Y & =(\text { lat2 }- \text { lat } 1) \\
& =(0.0021184077-0.0021813474) \\
& =-0.0000629397
\end{aligned}
$$

e. Mencari Nilai d (jarak)

\begin{tabular}{|c|c|c|c|}
\hline No. & $\begin{array}{c}\text { Latitude \& } \\
\text { Longitude } \\
\text { User }\end{array}$ & $\begin{array}{c}\text { Latitude \& } \\
\text { Longitude Titik } \\
\text { Kumpul }\end{array}$ & Jarak \\
\hline 1. & \multirow{5}{*}{$\begin{array}{l}\text { Lat : } \\
0.124982 \text {, } \\
\text { Long : } \\
117.49063 \\
\text { (Kantor } \\
\text { BPBD, Jl. } \\
\text { Ir. H. } \\
\text { Juanda) }\end{array}$} & $\begin{array}{l}\text { Lat : } \\
0.10933886, \\
\text { Long: } \\
117.48640023\end{array}$ & 1,80 \\
\hline 2. & & $\begin{array}{l}\text { Lat: } \\
0.13038761, \\
\text { Long: } \\
117.50092208\end{array}$ & 1,30 \\
\hline 3. & & $\begin{array}{l}\text { Lat : } \\
0.13706019, \\
\text { Long : } \\
117.48540339\end{array}$ & 2,05 \\
\hline 4. & & $\begin{array}{l}\text { Lat: } \\
0.12137582, \\
\text { Long : } \\
117.48472775\end{array}$ & 0,76 \\
\hline 5. & & $\begin{array}{l}\text { Lat : } 0.1302921 \\
\text { Long: } \\
117.48556425\end{array}$ & 0,76 \\
\hline
\end{tabular}

$$
\mathrm{d}=\operatorname{sqrt}(\mathrm{x} * \mathrm{x}+\mathrm{y} * \mathrm{y}) * \mathrm{R}
$$$$
=\text { sqrt }(0.0001030136 \times 0.0001030136
$$$$
+-0.0000629397 \times-0.0000629397) \times 6317
$$$$
=0.00012083045 \times 6317
$$$$
=0.76328 \mathrm{~km}
$$

Tabel 1. Tabel Perhitungan Jarak

\subsection{Perancangan Proses}

Untuk mempermudah memahami alur dokumen yang berjalan maka peneliti membuat rancangan dalam bentuk bentuk Flow Of Document (FOD). Alur FOD yang telah dibuat adalah sebagai berikut :

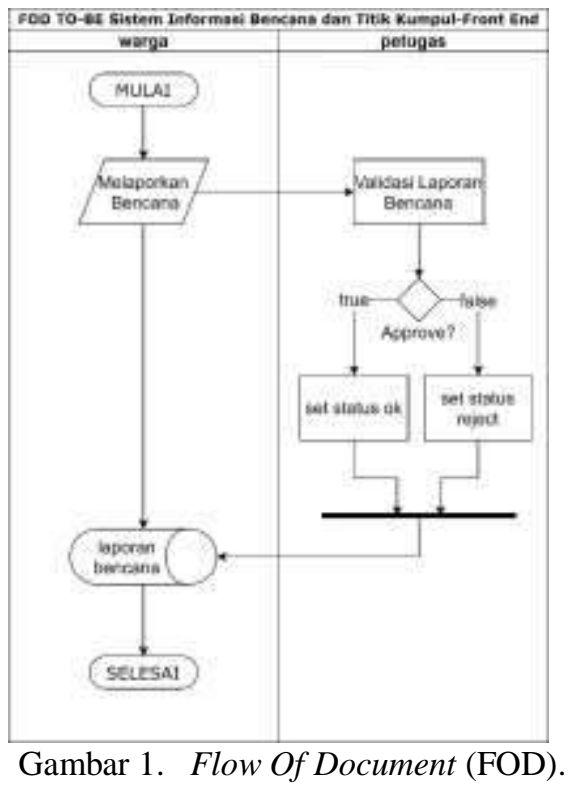

\subsection{Perancangan Sistem}

Perancangan sistem pada penelitian ini digambarkan dalam bentuk use case diagram. Pada use case diagram memberikan penjelasan terkait fungsi-fungsi dan fitur yang tersedia pada aplikasi. Berikut ini gambar use case yang digunakan untuk membuat aplikasi:

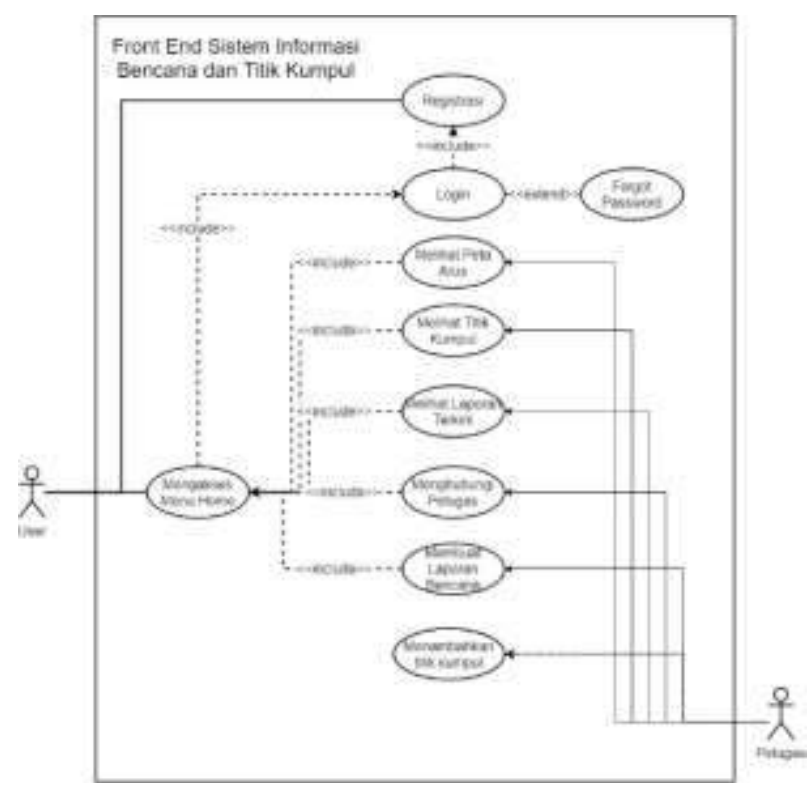

Gambar 2. Use Case Diagram

\subsection{Implementasi Antarmuka}

Implementasi antarmuka pada aplikasi yang telah dibuat adalah sebagai berikut:

a. Menu Home

Menu ini berisi tampilan utama dari aplikasi yang telah dibuat, tampilannya adalah sebagai berikut: 


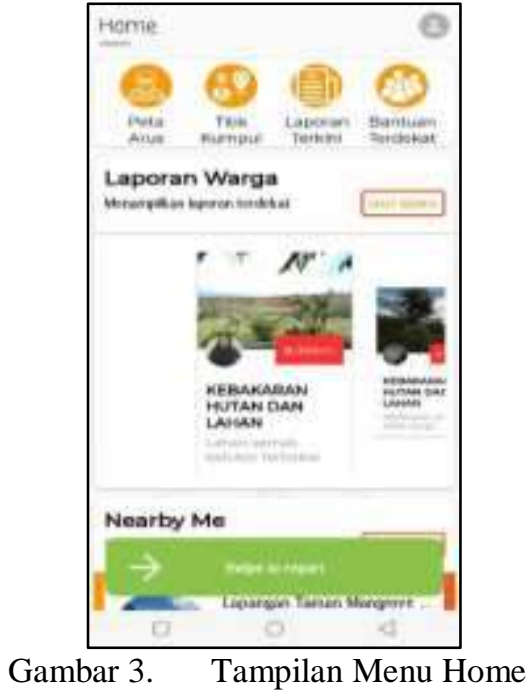

b. Menu Peta Arus

Pada menu ini berisi peta, arah mata angin, suhu, titik koordinat dan kecepatan angin.

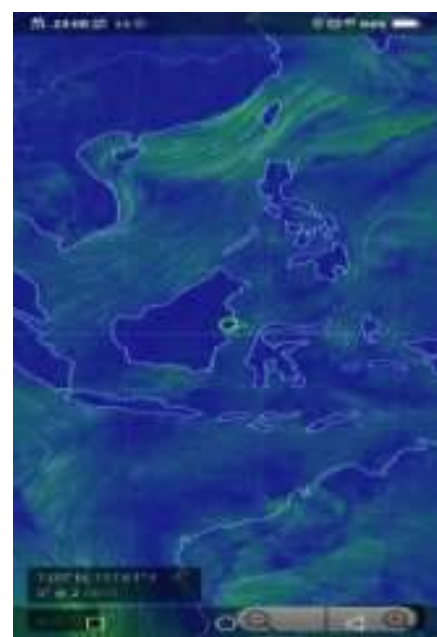

Gambar 4. Tampilan menu peta arus

\section{c. Menu Titik Kumpul}

Menu titik kumpul berisi informasi titik kumpul dan detail lokasi titik kumpul yang berada si suatu wilayah tertentu.

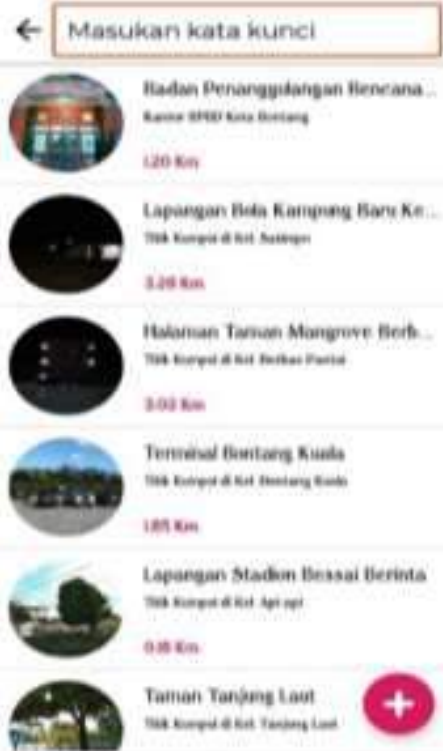

Gambar 5. Tampilan menu Titik Kumpul

d. Menu Laporan Terkini

Pada menu ini berisi informasi laporan yang dikirim oleh warga dan detail lokasi kejadian yang telah dilaporkan.

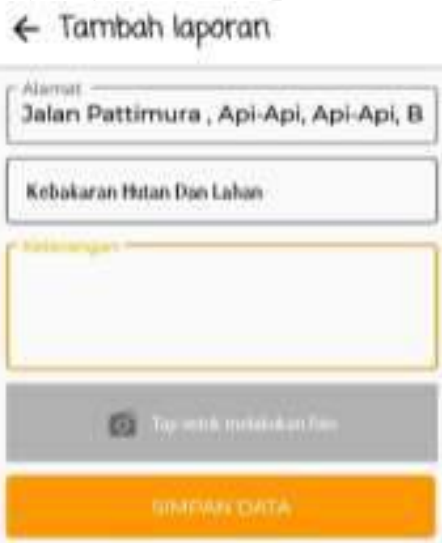

Gambar 6. Tampilan Menu Laporan Terkini

e. Menu Bantuan Terdekat

Pada menu ini, berisi kontak anggota BPBD agar user yang membutuhkan bantuan akan mendapatkan pertolongan dengan cepat, dapat memberikan notifikasi ke gawai petugas (admin) ketika Form Data Web Admin user aplikasi android menekan tombol bantuan terdekat pada menu aplikasi. Tampilan bantuan terdekat adalah sebagai berikut : 


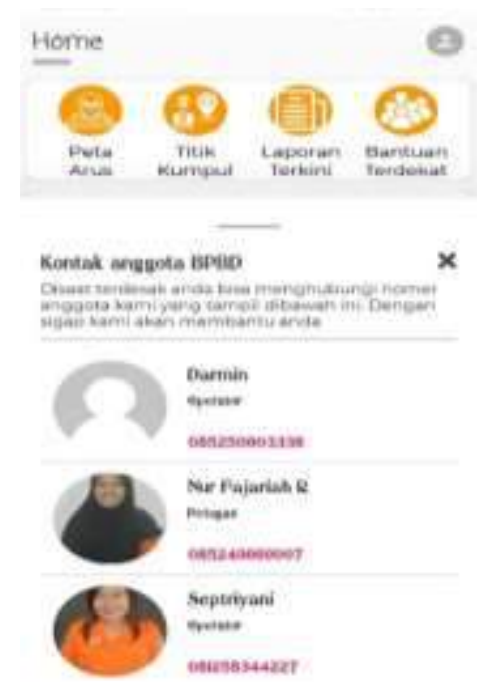

Gambar 7. Tampilan Menu Bantuan Terdekat.

f. Form Data Web Admin

Form Data Web Admin berisi data user, titik kumpul dan laporan bencana. Pada form ini admin dapat melakukan edit, hapus dan tambah.

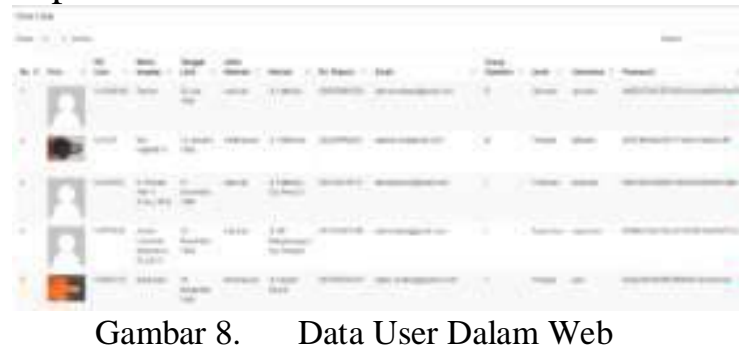

\subsection{Kode Program}

Kode program yang digunakan dalam aplikasi adalah sebagai berikut ini :

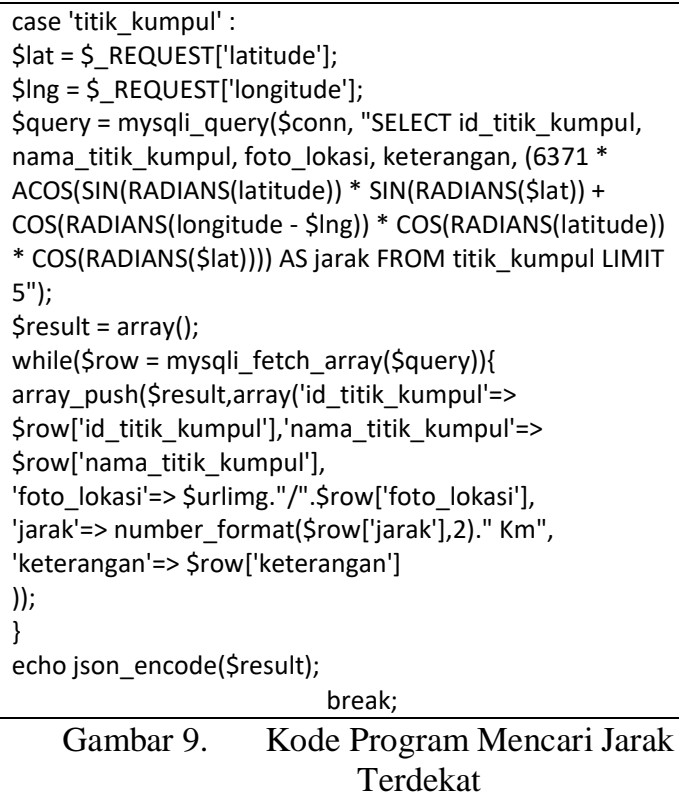

Gambar 9. Kode Program Mencari Jarak Terdekat

\section{Kesimpulan}

Dari penelitian masalah serta analisis dan pembuatan aplikasi ini, dapat di ambil kesimpulan bahwa:

a. Aplikasi informasi bencana dan titik kumpul berdasarkan jarak tempuh terdekat menggunakan metode Haversine Formula ini diimplementasikan pada smartphone berbasis Android.

b. Aplikasi informasi bencana dan titik kumpul ini menghasilkan jarak tempuh terdekat guna menghemat waktu, tenaga dan biaya.

c. Berdasarkan hasil dari analisis kuesioner uji kelayakan aplikasi, dari 10 responden menyatakan bahwa aplikasi informasi bencana dan titik kumpul ini layak digunakan dan dipublikasikan untuk masyarakat umum.

\section{Saran}

Saran yang disampaikan untuk pengembangan aplikasi ini untuk peneliti selanjutnya yaitu:

a. Penambahan beberapa fitur lainnya yaitu:

1. Pencarian objek lain.

2. Menambah foto untuk mempermudah detil lokasi.

3. Menambah suara pada saat melakukan navigasi menggunakan mobil tanpa harus melihat device mobile.

4. Memberi tanda suara jika lokasi yang di maksud sudah dekat atau sudah sampai.

5. Memberikan histori hasil pencarian agar mempercepat pencarian tanpa harus melakukan pendeteksian ulang lokasi user.

6. Memberikan kategori untuk bencana yang ingin ditampilkan.

b. Penggunaan metode lain yang lebih efektif juga bisa diteliti untuk mendapatkan hasil yang lebih baik.

\section{Daftar Pustaka}

[1] Badan Nasional Penanggulangan Bencana, "Potensi Ancaman Bencana," 2015. http://www.bnpb.go.id/pengetahuanbencana/potensi-ancaman-bencana.

[2] BNPB, "Definisi Bencana," Badan Nasional Penanggulangan Bencana, 2017. https://bnpb.go.id/definisi-bencana. 
[3] Pemerintah Republik Indonesia, "Undang-Undang Nomor 24 Tahun 2007 tentang Penanggulangan Bencana," Pemerintah Republik Indones., pp. 1-50, 2007, [Online]. Available:

http://www.litbang.depkes.go.id/sites/dow nload/regulasi/uu/UU_No._24_Th_2007_ ttg_Penanggulangan_Bencana.pdf.

[4] BNPB, "Sejarah Berdirinya BNPB," Badan Nasional Penanggulangan

Bencana, 2017.

https://bnpb.go.id/sejarah-bnpb (accessed Dec. 10, 2020).

[5] M. Carolina, "Kelemahan-Kelemahan Penanggulangan Bencana Alam di Indonesia," Buletin APBN, p. 3, 2018.

[6] W. Sanjaya, "Kurikulum dan Pembelajaran: Teori dan Praktik Pengembangan Kurikulum," Bandung: Rosdakarya, 2009.

[7] J. Hall, Accounting information systems. Nelson Education, 2012.

[8] "Pengertian Titik Kumpul." http://jasawebinstan.com/pengertian-titikkumpul/ (accessed Dec. 14, 2020).

[9] D. Prasetyo and K. Hastuti, "Penerapan Haversine Formula Pada Aplikasi Pencarian Lokasi Dan Informasi Gereja Kristen Di Semarang Berbasis Mobile," Skripsi Tek. Inform. Univ. Dian Nuswantoro, 2015.

[10] Z. P. Juhara, "Panduan Lengkap Pemrograman Android," Yogyakarta Andi Yogyakarta, 2016.

[11] M. S. Hasibuan, "Rute Trayek Angkutan Umum Dengan Google Api," J.

Teknovasi J. Tek. dan Inov., vol. 4, no. 1, pp. 28-31, 2017.

[12] B. Yuwono and A. S. Aribowo, "Sistem Informasi Geografis Berbasis Android Untuk Pariwisata Di Daerah Magelang," in Seminar Nasional Informatika (SEMNASIF), 2015, vol. 1, no. 1. 